\title{
CAREGIVER EXPERIENCES AND PERCEPTIONS OF STROKE
}

\section{Mary Thomas}

MA Psychology student

Department of Psychology, School of Human and Community Development, University of Witwatersrand

\section{Kirston Greenop}

$\mathrm{PhD}$

Lecturer, Department of Psychology, School of Human and Community Development, University of Witwatersrand Corresponding author: kirston@mindset.co.za

Keywords: stroke; perceptions; caregivers; content analysis

\begin{abstract}
With the increasing prevalence of people in developing countries who suffer strokes, the long-term care of people who have had a stroke and who are living with disabilities has substantial consequences for caregivers and their respective families. As the caregiver plays a pivotal role in the rehabilitation of the people who have had a stroke, the objectives of this study constitute an investigation into the complexities of caregiving, including both perceptions and experiences of the healthcare system. Semi-structured interviews were utilised to elicit post-stroke experiences of six caregivers. The challenge the South African context adds to these experiences was probed. The data were analysed qualitatively by thematic and content analysis. Prominent themes associated with caregiving included: role changes and relationship disruptions within the family, occupational and social implications, fatigue, anxiety, depression, loneliness, frustration as well as financial problems. Caregiver experiences were exacerbated by the inadequate support structures available. The results are interpreted within a biopsychosocial approach, concluding with the concerns raised by caregivers on the support they require from the healthcare system in order to provide home-based care.
\end{abstract}

\section{OPSOMMING}

Met die toenemende voorkoms van beroerte in ontwikkelende lande bring die langdurige versorging van pasiënte met gestremdheid beduidende gevolge vir sorggewers en hulle onderskeie gesinne mee. Aangesien die sorggewer ' $n$ sleutelrol in die rehabilitasie van die beroertepasiënt speel, behels die doelstellings van hierdie studie ' $n$ ondersoek na die verwikkeldhede van versorging, wat sowel persepsies as ondervinding van die gesondheidsorgstelsel ins/uit. Semi-gestruktureerde onderhoude is aangewend om die na-beroerte ondervindings van ses sorggewers te peil. Die uitdaging wat die Suid-Afrikaanse konteks tot hierdie ondervindings meebring is ondersoek. Die data is kwalitatief deur middel van tematiese en inhoudsanalise ontleed. Prominente temas wat verbandhou met sorggewing sluit in: rolverandering en verhoudingsteurnisse binne die huisgesin, beroeps- en sosiale implikasies, uitputting, angs, depressie, eensaamheid, frustrasie sowel as finansiële probleme. Die probleme van sorggewers word vererger deur ontoereikende steunstrukture. Die resultate word binne ' $n$ biopsigososiale benadering ontleed, en saamgevat met probleme wat sorggewers uitspreek ten opsigte van die steun wat hulle van die gesondheidsorgstelsel benodig om tuisgebaseerde sorg te kan voorsien. 


\section{INTRODUCTION}

The prevalence of stroke is growing in South Africa, particularly in the more rural areas (SASPI, 2004:627632), challenging the perception of stroke as a firstworld disorder. The onset of a stroke results in enduring changes in the lives of caregivers of people who have had a stroke as well as their respective families (King, Shade-Zeldow, Carlson, Feldman \& Philip, 2002:46-66), as the dynamics within the caregiving process are complex and multivariate (Bakas \& Burgener, 2002:3445). This study investigated this matter in detail through the administration of a semi-structured interview with six primary caregivers, in order to uncover the dynamics within the family system, as well as how these have evolved or changed following a stroke. A biopsychosocial perspective within systems theory provided the foundation on which these experiences were assessed, as this model directs attention toward the relationships and relationship issues between individuals (Becvar \& Becvar, 1996:3-13).

The family system needs to be conceptualised as a social unit embedded in a context of other such units, from health services to communities and society. Systems theory moves beyond the individualistic orientation, acknowledging the important role the family plays in the maintenance of health and reaction to illness (Akamatsu, Stephens, Hobfoll, \& Crowler, 1992:1-254), thus providing an appropriate frame for conceptualising the effects of stroke on the family. By integrating systems theory and the biopsychosocial model, one is able to identify and explore the experiences of the caregiver and family, working from a comprehensive and interdisciplinary perspective, as opposed to adopting one approach which may be flawed with limitations and thus fails to tap into the vital issues this research aimed to investigate.

Medically, a stroke is a focal neurological disorder involving decreased blood flow to and within the brain as a consequence of a pathological process in the blood vessels, thus making it vascular in origin (Lezak, 2004:194-201; Skilbeck,1992:339-359). The main pathogenic feature of stroke is the lack of nutrients (in effect, oxygen and glucose) to the brain, a result of the disrupted blood flow due to a blocked artery, which may stem from either thrombosis or embolism causing a tissue infarction (Skilbeck, 1992:339-359). In addition, bleeding from an artery may occur spontaneously which produces intracerebral or subarachnoid haemorrhaging (Skilbeck, 1992:339-359). With the nervous tissue of the brain incapable of surviving more than a few minutes of oxygen deprivation, irreversible brain damage commonly occurs. The disruption of blood flow (infarction), leads to a damaged area of tissue referred to as an infarct (Lezak, 2004:194-201). The neurological effects last more than 24 hours and produce persistent effects (Skilbeck, 1992:339-359). Stroke affects no specific region or blood vessels and so a prediction of cognitive and behavioural effects cannot be made (Skilbeck, 1992:339-359). Stroke has predominantly has one-sided effects, meaning the effects tend to be localised to either the left or right hemisphere of the brain, and these infarcts in turn cause deficits on the opposite or contralateral side of the body. There is a vast difference between people who have had a stroke in terms of depth, extent, and site of damaged tissue. However, electrological studies using Computerized Tomography (CT) and Magnetic Resonance Imaging (MRI) scans have revealed that lasting alterations of functions of the brain may be distant from the actual lesion. Secondary diffuse effects occur during the acute stages, and are thus considered additional symptoms of widespread brain pathology, although symptoms may improve in the primary stages of the illness. These secondary effects, such as swelling, can result in serious bilateral or diffuse damage. As the swelling decreases so the bilateral or diffuse dysfunction gradually improves along with lateralised impairments (Lezak, 2004:194-201). Site as well as size of lesion is associated with level of improvement in functioning (Knopman, Selnes, Niccum \& Rubens, 1984:1461-1470).

Psychologically, motor and cognitive impairments may result in depression, social isolation (King et al. 2002:4666), and a change in self-concept which may induce an increased level of anxiety (Ellis-Hill \& Hom, 2000:279287). Other emotional reactions to stroke include emotional lability, apathy (lack of emotions), low self-esteem, anger, and frustration (Zillmer \& Spiers, 2001:297316). Symptoms of depression increase in severity in the later stages of recovery (Magni \& Schifano, 1984:567-571). Starkstein and Robinson (1992, cited in Lezak, 2004:194-201) found that 30\% of patients who failed to exhibit symptoms of depression on discharge, became depressed later. Post-stroke depression is multifactorial in origin and commonly associated with 
excess disability, cognitive impairment and mortality (Whyte \& Mulsant, 2002:253-264). These emotional disturbances may be a direct consequence of the infarct, or depression (post-stroke) may be associated with coping with the challenges of this condition. $\mathrm{Pa}$ tients tend to experience a different relationship with their bodies, their families and society (Ellis-Hill \& Hom, 2000:279-287). Therefore, its consequences are widespread and include physical, social, personal and economic considerations (Fritz \& Penn, 1992:1-3). The medical, psychological and social effects of a stroke extend beyond the patient to their family and caregivers.

Experiencing a stroke in the family is disruptive to family roles as caregiving tasks are assumed. Emotions of anxiety, depression, guilt, anger, as well as resentment may be experienced by the caregiver (Hartke \& King, 2002:16-33) as stroke not only affects physical function but emotion, memory and thinking, communication, and quality of life (Lai, Studenski, Duncan \& Perera, 2002:1840-1844). However, family members describe the disturbance in the patient's communication ability as the most stressful and difficult factor with which to cope (Van Veenendaal, Grinspun \& Adriaannse, 1996:265-276).

Multimethod studies focusing on the caregiver's subjective experience of 123 elder spousal caregivers in America revealed difficulties in various spheres of life, including: emotional distress, learning new skills and assuming new roles, coping with the healthcare system and limited resources, relationship disruption, as well as social constraint (Hartke \& King, 2002:1633). Family members are also reported to struggle with social isolation, behavioural problems, financial strain and sleep disturbances (Van Veenendaal, Grinspun \& Adriaannse, 1996:265-276). Malone (1969:146-151) echoed these reactions and identified nine major themes that describe the effects of stroke on the family. These included: role changes, irritability of family members, guilt feelings, altered social life, financial problems, health problems, vocational problems, rejection or over-protectiveness of the spouse caused by ignorance of how to interact with the patient, and effects on children. Sexual problems may be an additional consequence of the disability and should be addressed, as sexual adjustment counselling is an integral part of the rehabilitation process (Fritz \& Penn, 1992:131-161).
Loneliness, depression, and a sense of burden are three forms of distress that have been associated with negative adaptation to caregiving. Depression, which is the most frequently documented (Hartke \& King, 2002 :16-33), is reported as occurring in $34 \%$ to $52 \%$ of caregivers. In some cases the depression scores of caregivers have been higher than those of patients. Characteristics of people who have had a stroke such as stroke severity, physical impairment, patient's level of depression, as well as negative personality characteristics have been associated with the depression experienced by the family caregiver. Additional emotional distress factors are low caregiver self-esteem, high task difficulty, and high threat appraisal (Bakas \& Burgener, 2002:34-45). Negative emotional states have been correlated with the nature of functional disability in the patient, as the caregiver's quality of life depends greatly on the patient's level of disability, the more the person who has had a stroke can achieve alone the better their relationship, as it reduces resentment felt on both sides (Hartke \& King, 2002:16-33).

Spouses are the most probable caregivers as stroke is more prevalent in the elderly. Caregivers' senior ages as well as health problems place them at risk for morbidities due to the stress of caregiving. Distress, anxiety and loss of income, as well as the need to take on novel tasks formerly the responsibility of the patient, reflects the burden the caregiver carries and stressrelated diseases, such as high blood pressure, duodenal ulcers and heart disease may result (Hartke \& King, 2003:65-81).

Han and Haley (1999:1478-1485) found that few studies focused on reducing the pressures families are confronted with. There is a need to consider the combined effect of education and support in assisting caregivers in their role as they are often unprepared and overwhelmed by the demands and responsibilities that define the role of a caregiver. Caregivers of individuals with cognitive impairments are in need of support and input particularly on the challenges of behaviour management. Between $45 \%$ and $49 \%$ of patients and their caregivers are dissatisfied with the pre-discharge information received concerning stroke, whilst caregivers' coping abilities are increased by stroke information (Low, Payne \& Roderick, 1999:711725; O'Connell, Baker \& Prosser, 2003:21-28). Family 
members have reported being less informed than patients (Van Veenendaal et al. 1996: 265-276). Sources of assistance, strategies for daily activities, and precautions to reduce the onset of another more debilitating stroke (Denby \& Harvey, 2003:34-45; Van Veenendaal et al. 1996: 265-276), and limited contact with psychologists and neuropsychologists affect the ability for the caregivers to carry out their role (Bowen, Tennant, Neuman \& Chamberlain, 2001:29-38). Furthermore, most caregivers are uninformed of the costs of nonmedical care and options for medical aid coverage (Moscowitz, 2002:75-86).

While international research has identified numerous areas of challenge to caregivers, the literature on South African caregivers is scant (Bham \& Ross, 2005:548554; SASPI, 2004:627-632). Where literature does exist, this appears to concentrate on medical and neurological aspects of stroke (Kahn \& Tollman, 1999:63-65; Kahn, Tollman, Garenne \& Gear, 1999:433-441; Penn, 1999:535-552, 2002:185-189; Penn, Venter \& Ogilvy, 2001:111-132), rather than on the psychosocial aspects of caregiving. This study aimed to address the impact of stroke on the family system in an interpretative and in-depth manner, unpacking caregivers' experiences and perceptions whilst mindful of the multi-dimensional effects of stroke in terms of environmental and situational influences. Two research questions were investigated:

- What are caregivers' perceptions of the biological, psychological and social effects of stroke on the family system?

- What are caregivers' perceptions and experiences of the medical and psychological services available for people who have had a stroke?

\section{METHOD}

\section{Design}

This research was qualitative in design and utilised content and thematic analysis to interpret the results of semi-structured interviews (Henning, Van Rensburg \& Smit, 2004:146). Participants were selected based on the criteria of being a caregiver and attending a government hospital.

\section{Participants}

Non-probability purposive sampling was used to select participants. Caregivers were recruited from the Neurovascular Clinic of a Johannesburg-based government hospital.

Selection was based on the following inclusion criteria:

- A twelve month post-stroke adaptation period. This allowed a sufficient period of adjustment and the long-term biopsychosocial effects associated with stroke for both the person who has had a stroke and caregiver to be experienced.

- The person who has had a stroke had to reside within the same residence as the caregiver. Therefore, institutionalised individuals were not included in the study.

- The caregiver had to be the spouse or child of the person who has had a stroke, in other words the primary caregiver.

Specifications were not adopted regarding gender, race, or culture; instead suitable volunteers from the public clinic who fitted the inclusion criteria were invited to participate (see Table 1 for the demographic details of the sample). While the selection criteria excluded many individuals, all caregivers approached to participate volunteered. The sample consisted of individuals from low or lower-middle socio-economic backgrounds who were conversant in English. In order to meet the criteria specified to ensure the validity of results, six participants were interviewed.

\section{Procedure}

A semi-structured interview consisting of open-ended questions was conducted. This enabled probing whilst allowing flexibility on the part of the researcher. The open-ended questions were 'funnel type' in nature, starting with broad questions and moving to more specific, narrow questions as the interview progressed (Rosenthal \& Rosnow, 1991:188). Flexibility was imperative for this type of study as it provided the opportunity to explore issues working with interviewee responses.

A pilot study assessed the structure of the questions 
Table 1: Demographic details of caregivers that partook in the study

\begin{tabular}{lllllll}
\hline Age & Gender & Race & $\begin{array}{l}\text { Number of } \\
\text { children }\end{array}$ & $\begin{array}{l}\text { Relation to person } \\
\text { who has had a } \\
\text { stroke }\end{array}$ & $\begin{array}{l}\text { Time since } \\
\text { stroke }\end{array}$ & $\begin{array}{l}\text { Type } \\
\text { stroke }\end{array}$ \\
\hline 49 & Male & Coloured & 2 & Husband & 13 yrs ago & Thrombosis \\
37 & Female & White & 2 & Daughter & 2 yrs ago & Thrombosis \\
56 & Female & White & 2 & Wife & 4 yrs ago & Thrombosis \\
58 & Male & White & 3 & Husband & 1.5 yrs ago & Aneurysm \\
67 & Female & White & 3 & Wife & 3 yrs ago & Unknown* \\
16 & Female & Black & 0 & Daughter & 3 yrs ago & Unknown* \\
\hline
\end{tabular}

*Note: Information regarding the type of stroke sustained by two of the people who have had a stroke was not available in their medical records and nor was the person who has had a stroke or caregiver provided with this information by a physician.

and enabled the researcher to check for ambiguity. Revisions of the interview questions were made accordingly. The above process ensured validity in the process as continuous checking of the interview structure, design and process was made. The interview was linked to the theoretical review of the area. Following Henning et al. (2004:148-149) the evidence and process was continually checked for bias, neglect and interpretation, all statements and comments were questioned and links to theory were made throughout the process. Lastly, interpretations and actions were shared and discussed with peers and fellow researchers.

Care was taken to ensure the interviews were conducted in a quiet, private setting at the Neurovascular Clinic. No incentive to participate in the study was offered. The interviews were conducted by one of the researchers and all were audio-taped and transcribed verbatim.

\section{Data analysis}

Analysis of the data took the form of thematic and content analysis. The objective was to provide an accurate and coherent picture of caregivers, by describing the processes, mechanisms and relationships in their daily lives. As such, the researchers were intricately involved in all aspects of the research from the outset and were well positioned to analyse and code the data (Henning et al. 2004: 106).
The questions were structured to tap into the theoretical framework. Themes from the literature on stroke included: role changes, irritability of family members, feelings of guilt, altered social life, financial problems, health problems, occupational problems, sexual problems, rejection or over-protectiveness of the spouse caused by ignorance of how to interact with the patient, and effects on children, as well as inadequate medical and psychological services (Bowen et al. 2001:29-38; Denby \& Harvey, 2003:34-45; Low, Payne \& Roderick, 1999:711-725; Malone, 1969:146-151; O'Connell, Baker \& Prosser, 2003:21-28; Van Veenendaal et al. 1996:265-276; Zillmer \& Spiers, 2001:297-316). The researcher probed these themes, whilst being open to new themes.

\section{Ethical considerations}

Ethical clearance was obtained by the relevant ethics committee. Furthermore, permission from the Neurovascular Clinic was granted by the senior consultant neurologist. The senior psychologist of the hospital also agreed for participants to be referred to her for counselling if the need arose.

Participants were fully informed on the study and that participation was voluntary. The participants provided written consent to partake in the study. Confidentiality was guaranteed by a system of coding which was employed to protect the identity of the participants, and the audiotapes were deleted after use. 


\section{RESULTS AND DISCUSSION}

Due to the semi-structured nature of the interview the results of the study will be discussed based on identified themes and sub-themes.

\section{The caregiver family system}

All the participants lived with the person who has had a stroke as per the study's inclusion criteria, however, in the case of four of the six participants other family members also resided in the same household. The two participants who lived alone with the person who has had a stroke did not receive the additional assistance and support the other caregivers may have experienced from family members. One of these two caregivers was a black 16-year old daughter of a person who has had a stroke who received no familial support at all. This one instance supports the nature of the urban family as she resided in central Johannesburg.

\section{Reintegration}

Living with family members was not always supportive. Two of the four participants who lived with other family members reported difficulties concerning their living arrangements. These were perceived to be based on the feelings of the people who have had a stroke, who found it challenging to adjust to post-stroke conditions, with the caregivers stating, " ...he feels it is not his home, we are living with my daughter and her husband, they support us, and my husband struggles with that" and, "My wife wants us to move out but I am not able to financially, she feels that our sons don't understand her and she keeps saying she needs to get out of this environment". Importantly, both couples lived on their own prior to the stroke which may have influenced these reactions.

The emotional consequences of stroke such as emotional lability, anger, frustration, apathy and low selfesteem (Zillmer \& Spiers, 2001:297-316) had a substantial effect on the caregiver, illustrated through the complex process of reintegration into the family system post-stroke. Caregivers perceived this as increased pressure and stress to manage. Systems theory argues that each family member needs to adjust to the altered situation post-stroke and restore the equilibrium of the system. This is a strenuous time for all involved, and coping styles may vary for each family member (Faison, Faria \& Frank, 1999:215-233). This search for equilibrium is experienced as an additional stressor for the caregiver, as is the development of coping strategies during this multifaceted process.

\section{Children}

Malone (1969:146-151) emphasises the effect on children as a consequence of stroke. The sub-theme of children appeared to emanate only in the case where the children of the person who has had a stroke were young and still living at home, whereas negative ramifications for elder independent children even in cases where the person who has had a stroke was residing with them, was not as strongly expressed. The challenges faced by the young children of the person who has had a stroke in the present study included being teased about their parent's disability at school, and having a great deal of responsibility from a young age resulting in increased coping skills due to their circumstances.

Two other participants mentioned that the person who has had a stroke has a poor relationship with his/her children, placing the caregiver in a compromising position. This intensifies the challenges of caregiving. This emerged from two participants whereby the strained relationship between the person who has had a stroke and their children proved particularly difficult for the caregiver as they were forced to mediate between their spouse and their children, stating, "I'm stuck in the middle", and "... my wife has become withdrawn since her stroke and feels that no-one likes her anymore. She says she feels wooden, so I go between my wife and sons". This places an additional strain on the caregiver and may be a precipitating factor to pathology within this population (Hartke \& King, 2002:16-33).

\section{Relationships}

Perceptions and experiences of the relationships within the family system post-stroke elicited a diverse range of responses from, "...explosive at times", "Negative..." to, "Very good" and "We are close". One participant felt that the stroke brought the family closer together. This was reported by the young, black, female participant who was caring for her mother on her own. The other 
five participants, however, considered the period poststroke to be one of great adjustment.

One caregiver mentioned that the family became less supportive over time after the stroke. A participant, who was the wife of the person who has had a stroke, found that their relationship had changed following the stroke although his relationship with his children had not altered. She mentioned that, "He is sometimes like a child, very childish and that irritates me". She also stated that, "He also cries a lot. He wasn't like that before".

Role reversal was also highlighted as an issue that was difficult to adjust to, "In the past my wife was the strong one, so our roles had reversed". Family relationships were more strained when family members resided in the same house.

\section{Tasks of caregiving}

The tasks associated with caregiving for the participants included:

- $\quad$ Monitoring that the patient does not have a seizure, another stroke, or place themselves or others in danger, for example, forgetting to switch off the stove.

- $\quad$ Bath and dress the patient.

- Ensure the patient receives their medication.

- Assist the person who has had a stroke with physical activities, such as climbing stairs.

- Attend to household chores.

- $\quad$ Taking care of children.

The 16-year daughter caregiver reported: cooking, cleaning the house and bathing the patient whilst still attending school. One caregiver stated, "I'm always there for him, he is never there for me", whilst another verbalised, "He goes to bed at 7 o'clock and I sit and watch TV alone". These negative connotations indicated an additional sub-theme of loneliness in participants having similar family systems: mature children who have families of their own, and their spouse their only companion (Hartke \& King, 2002:16-33). This experience has a strong link with the psychosocial and neurological ramifications of stroke for the person who has had a stroke, which sequentially affects the caregiver as well as the entire family system as each member of the system is influencing and being influenced simultaneously (Becvar \& Becvar, 1996:357-359). The expe- riences of the family system were exacerbated by the disability and behaviour of the person who has had a stroke.

Three participants reported experiencing their role as adequate, "Good, coping with it", "It's alright, I'm used to it no"', and, "Its ok, I'm coping with it". These responses were categorised as well-adjusted, as equilibrium within the family system was restored; whilst the other three participants' responses involved detailed descriptions of the tasks they perform as caregivers, thus illustrating experiences of difficulty in the caregiving role.

The most challenging task of caregiving was specific to each caregiver. Responses included the issue of time, "Time. You don't have a life of your own - no time to yourself... having to take on all the responsibilities of child rearing...", role reversal (particularly with caregivers who were children of the person who has had a stroke), mediating between the patient and others due to their poor communication skills, the emotional side of the patient including their labile emotional state, financial difficulties, and transport issues (specifically transport for attending medical appointments as there is no family support), "I have to miss school to come, my family doesn't help us, we catch a taxi here". These responses comprised the most prominent themes associated with the negative aspects of caregiving. Only one participant mentioned communication to be the most stressful factor to cope with, although this was identified as a primary stressor in a study by Van Veenendaal et al. (1996: 265-276).

The results illustrate the impact severity and type of stroke has on the caregiving role. Interestingly, most participants interpreted the question in terms of their physical role, daily activities and did not emphasise relationships and emotional issues.

\section{Fatigue and stress-related illnesses}

Elevated levels of fatigue as a result of caregiving were expressed by four participants, with one participant stating that, “... I also get sick often. I have continuous lung infections from stress. I'm on antidepressants as well". Stress-related illnesses in caregivers due to immune depletion have been previously documented (Hartke \& King, 2003:65-81; Malone, 1969:146-151), 
along with sleep disturbance leading to fatigue (Van Veenendaal et al. 1996:265-276).

It was interesting that the 16-year old participant only expressed difficulty in caregiving when asked the question concerning physical difficulties related to caregiving, responding with, "I sometimes get tired but I have to do it because she's my mother", reflecting her perception of caregiving as duty, and not as a burden per se. Her ability to identify with the more physical aspect of caregiving as opposed to the emotional dimension may be due to her age, culture, and ability to express difficulty. Physical stressors are easier to identify and accept than psychological, emotional or social stressors. In addition, psychological or social stressors may manifest in a physical manner. These findings point to a need for further research into different age and race groups as caregivers. There were no obvious gender specific themes; one male participant found caregiving physically challenging, whilst the other did not.

\section{Emotions}

One participant recounted his experience of burn-out two years after the stroke, “... I 'conked in'. I had reached burn-out and had a panic attack... If you don't have support you've had it". He also noted the financial strain associated with caregiving together with the importance of a support network. Another participant also referred to her support system, "When I get upset I call my daughter and she supports me". The continuous worrying or anxiety about the possibility of the patient experiencing another stroke was a pressing issue for one participant, "I just worry about him all the time...", whilst the psychological impact of the financial strain was mentioned by two caregivers. Depression and feeling "annoyed" was also expressed by one participant. A theme that emerged quite strongly was the need to watch the person who has had a stroke on a continual basis resulting in elevated levels of anxiety. This finding echoes results of international research which found anxiety to be a primary emotional outcome of the caregiving process (Hartke \& King, 2002:16-33).

The fundamental psychological themes associated with caregiving included: depression, frustration, loneliness and anxiety. The primary precipitating factor to these emotions was financial strain.

\section{Expressed emotion}

There were two male and four female participants and the researchers found the male and female participants equally responsive and emotive. Conversely, other research in this area has found women more likely to express the difficulties associated with their caregiving role (Hartke \& King, 2003:65-81). Perhaps the data collection environment, sampling technique and instrument used allowed all participants to feel comfortable to express themselves freely. Furthermore, the confidential nature of the study may have been an additional factor that promoted open communication.

\section{Work}

Work related themes included having to take time off work to take the person who has had a stroke to medical appointments and feeling anxious at work, "When I did work I used to worry about him all the time". One participant had to resign in order to take care of the person who has had a stroke as he required the care of a nurse which proved too costly for them. Noteworthy, is the recurring theme in the present study of the financial strain placed on the family of people who have had a stroke (Hartke \& King, 2003:65-81; Malone, 1969:146-151; Van Veenendaal et al. 1996:265-276). Family members of people who have had a stroke have been reported to struggle with emotional distress and financial strain (King et al. 2002:46-66; Malone, 1969:146-151; Van Veenendaal et al. 1996:265-276).

\section{Social life}

Social ramifications were experienced, with one participant highlighting the effect stroke has had on the social life of their children, "The kids used to love camping, but now they have to go with friends, my wife can't do that. They also love going to the movies but my wife is sensitive to light so we don't go anymore. One of us has to stay with my wife at all times, we take turns. I miss the spontaneity; the stroke restricts our lives...". Three participants stated that their social lives had been affected. The noteworthy comment by one caregiver concerning the effect on the entire family system, "...stroke restricts our lives", ties in with Hartke and King's (2002:16-33) study which highlighted the sense of burden experienced by caregivers of people 
who have had a stroke, along with the association between caregiver distress and type and severity of stroke impairments (Bakas \& Burgener, 2002:34-45). Predictably, the greater the disability the more demanding the role of the caregiver and the more adaptation is required on the part of the family.

\section{Coping strategies}

One caregiver considered their long marriage to be a factor encouraging coping, stating, “... it's harder to work through when you're younger", yet another felt that age was a driving force as their whole lives were still ahead of them and the couple had young children, he also mentioned "....we get external help", illustrating the importance of social support to increase coping. The responses exhibit different types of emotion-focused coping based on the unique circumstances of each family system with length of relationship and social support being factors which enhanced coping skills for caregivers. Establishing social support was considered the most important approach to increase coping based on the responses of two participants. The importance of support is also consistent with literature on coping with stroke which found that education and support assisted caregivers in their role (O'Connell, Baker \& Prosser, 2003:21-28).

Based on the comments of the participants and relating caregiver responses to the length of time post-stroke, it was evident that the more time the family system had post-stroke, the better adapted they became. Interestingly, this was even true in the event of lessening social support. In response, these caregivers actively sought social support depicting emotion-focused coping strategies (Folkman, 1984:839-852).

According to Hartke and King (2003:65-81) mediators such as care skills, education regarding disability, and a support system, can positively influence coping and distress. These variables act as buffers. Based on the participants' opinions, this premise was validated in the present study as those with established support networks and education on stroke had superior levels of coping.

\section{Healthcare services}

The health services received from the public sector were relatively well perceived by five of the six participants, whereas the two participants who had been treated in private hospitals prior to their admission to a government hospital were dissatisfied by the service they received in the private sector due to the lack of post-stroke information provided by the private clinic.

The complaints concerning the public hospital included the lack of continuity as different registrars work at the clinic, a lack of general information regarding stroke, "There is no after care advice... I've learnt how to handle $i t$ ", and its disorganised nature. Two of the caregivers were referred for psychological help by the consulting neurologist; however, the other four participants did not receive any information on the psychological impact of stroke on the patient or the family.

Four of the participants stated that no educational information on stroke prevention was provided. The importance of education in terms of preventing another stroke and providing support has been greatly emphasised in the literature (Han \& Haley, 1999:14781485; O'Connell, Baker \& Prosser, 2003:21-28; Van Veenendaal et al. 1996:265-276), and is thus an issue which urgently needs to be addressed by the medical community. Furthermore, family therapy improves interaction between family members, thus facilitating coping (Fritz \& Penn, 1992:131-161) and should therefore be discussed by the consulting physician as an option for the family.

Recommendations for improvement suggested by the participants included: providing pamphlets and brochures on post-stroke care, running the stroke clinic in the morning as patients tire quickly and often have to return the following day as the medicine dispensary closes or alternatively dispense medication from the clinic, and the treatment of the patients needs to improve, "...shouldn't treat the patient like a number". An additional concern was the lack of social support for younger people who have had a stroke outside the hospital as many stroke organisations accommodate older patients as stroke is relatively age related and if young, "... felt out of place". This highlights a need to accommodate younger people who have had a stroke.

\section{SUMMARY}

The present study explored the biological, psychologi- 
cal and social dimensions of caregiving; whilst acknowledging the interaction within each family system as well as the influence healthcare systems adds to their experiences. Effects of stroke were experienced by the caregiver on many levels. Prominent themes and subthemes concerning the difficulties of caring for a person who has had a stroke included: role changes, relationship disruptions within the family system as the period post-stroke was perceived by most as one of adjustment, emotional lability as a consequence of consistent monitoring of the patient as well as the physical challenge of caregiving, social implications due to outsiders' perceptions and loss of independence, psychological ramifications such as depression, anxiety, frustration and loneliness, occupational implications, and financial problems. An additional point was that the participants found that the younger the children the greater the effect of stroke on them. However, as previously mentioned, the more support in the form of psychotherapy and practical and emotional assistance from extended family and friends, the greater the ability to cope. Social support was emphasised, with coping strategies constituting social support, psychotherapy as well as the perception of caregiving as a duty. Five participants found areas of caregiving to be difficult, having biological, psychological and social effects for them and their respective family systems.

As the family system is embedded in the context of other systems from health services to their community and society, issues concerning the healthcare system were investigated. These services were perceived positively by five of the six participants, however, when asked if they had received any education post-stroke, four participants considered this to be a fundamental problem. Inadequate post-stroke information was congruent with other studies in this area which emphasise the need to improve this issue thus enhancing caregivers' coping abilities, whilst assisting the person who has had a stroke and caregiver in terms of stroke prevention. Additional themes concerning the healthcare services in South Africa included less than ideal continuity of care as well as disorganisation of government clinics with state healthcare services being perceived more positively than those of the private sector.

\section{CONCLUSION}

Systems theory and the biopsychosocial approach provided a beneficial framework to explore the entire context of the caregivers' experiences. This theoretical perspective allowed for various dimensions of the caregiving process to be investigated, thus providing comprehensive results which considered interaction across multiple levels.

The primary limitation of this study was its sampling technique, as the sample was selected based on a non-probability sampling method. This implies that conclusions of this study cannot be generalised to the entire stroke population, family members, and services rendered as the participants may not be representative of the general population. Having stated these limitations, the methodology employed by the present study aimed to provide an exhaustive view into the effects of stroke on the family system, looking at these effects on many levels, whilst acknowledging the influence the South African context adds to these experiences.

This study may be used as a pilot study for the formulation of an inventory that assesses the mental health of families affected by stroke. As there is insufficient research conducted in African countries concerning caregivers and their experiences of caregiving, this study provides unique information in this particular area of research, in terms of its interpretive perspective and local focus. In this way, it is beneficial and significant to caregivers as well as families affected by stroke. In addition, it highlights particular gaps within the medical, psychological and social work systems that are in need of attention and further development. Addressing these issues would result in an enhanced person who has had a stroke care due to the increased knowledge and coping skills of caregivers which, in turn, would have a positive impact on the rest of the family system thus facilitating their period of post-stroke adjustment.

With restrictions on resources in the South African healthcare systems, patients are discharged to the care of their families. These caregivers need to be equipped with the appropriate information and support to fulfil the challenging and demanding role of caregiving and thus assist the persons who have had a stroke with their 
rehabilitation. The present study identified various areas of caregiving having biopsychosocial consequences for caregivers and their respective families. Furthermore, results indicated a lack of post-stroke information from health care workers. Caregivers and families need to be empowered in order to assume more effective caregiving roles which may be achieved through greater multi-disciplinary healthcare intervention so that caregivers are trained and empowered on the various aspects of caregiving which is so multivariate in nature. This requires the assistance of healthcare professionals so that families of people who have had a stroke increase their capacities for illness management and coping skills therefore, referrals between healthcare professionals are recommended so that caregiver needs are addressed on a multidimensional level.

\section{REFERENCES}

AKAMATSU, TJ; STEPHENS, MAP; HOBFOLL, SE \& CROWLER, JH 1992: Family health psychology. Washington DC, USA: Hemisphere Publishing Corporation.

BAKAS, T \& BURGENER, SC 2002: Predictors of emotional distress, general health, and caregiving outcomes in family caregivers of stroke survivors. Topics in Stroke Rehabilitation, 9(1):34-45.

BHAM, Z \& ROSS, E 2005: Traditional and western medicine: Cultural beliefs and practices of South African Indian Muslims with regard to stroke. Ethnicity and Disease, 15(4):548-554. BECVAR, DS \& BECVAR, RJ 1996: Family therapy: A systemic integration; $3^{\text {rd }}$ edition. Boston: Allyn \& Bacon.

BOWEN, A; TENNANT, A; NEUMAN, V \& CHAMBERLAIN, AM 2001: Neuropsychological rehabilitation for traumatic brain injury: Do carers benefit? Brain Injury, 15(1):29-38.

DENBY, F \& HARVEY, RL 2003: An educational intervention for stroke rehabilitation patients and their families: Healthy living after stroke. Topics in Stroke Rehabilitation, 9(4):34-45.

ELLIS-HILL, CS \& HORN, S 2000: Change in identity and selfconcept: A new theoretical approach to recovery following a stroke. Clinical Rehabilitation 2000, 14(3):279-287.

FAISON, KJ; FARIA, SH \& FRANK, D 1999. Caregivers of chronically ill elderly: Perceived burden. Journal of Community Health Nursing, 16(4):215-233.

FOLKMAN S 1984: Personality control and stress and coping processes: A theoretical analysis. Journal of Personality and Social Psychology, 46(4):839-852.

FRITZ, V \& PENN, C 1992: Stroke: Caring and coping. Johannesburg: Witwatersrand University Press.

HAN, B \& HALEY, WE 1999: Family caregiving for patients with stroke: Review and analysis. Stroke, 30:1478-1485.

HARTKE, RJ \& KING, RB 2002: Analysis of problem types and difficulty among older stroke caregivers. Topics in Stroke Rehabilitation, 9(1):16-33.

HARTKE, RJ \& KING, RB 2003: Telephone group intervention for older stroke caregivers. Topics in Stroke Rehabilitation, $9(4): 65-81$.

HENNING, E; VAN RENSBURG, W \& SMIT, B 2004: Finding your way in qualitative research. Pretoria: Van Schaik.

KAHN, K \& TOLLMAN, SM 1999: Stroke in rural South Africa Contributing to the little known about a big problem. South African Medical Journal, 89(1):63-65.

KAHN, K; TOLLMAN, SM; GARENNE, M \& GEAR, JS 1999: Who dies from what? Determining cause of death in South Africa's rural North-East. Tropical Medicine and International Health, 4(6):433-441.

KING, RB; SHADE-ZELDOW, Y; CARLSON, CE; FELDMAN, JL \& PHILIP, M 2002: Adaptation to stroke: A longitudinal study of depressive symptoms, physical health, and coping process. Topics in Stroke Rehabilitation, 9(1):46-66.

KNOPMAN, DS; SELNES, OA; NICCUM, N \& RUBENS, AB 1984: Recovery of naming in aphasia: Relationship to fluency, comprehension and CT findings. Neurology, 34:1461-1470.

LAI, S; STUDENSKI, S; DUNCAN, PW \& PERERA, S 2002: Persisting consequences of stroke measured by the stroke impact scale. Stroke, 33:1840-1844.

LEZAK, MD 2004: Neuropsychological assessment; $3^{\text {rd }}$ edition. Oxford: Oxford University Press.

LOW, JTS; PAYNE, S \& RODERICK, P 1999: The impact of stroke on informal carers: A literature review. Social Science and Medicine, 49:711-725.

MAGNI, G \& SCHIFANO, F 1984: Psychological distress after stroke. Journal of Neurology, Neurosurgery and Psychiatry, 47(5):567-571.

MALONE, RL 1969: Expressed attitudes of families of aphasics. Journal of Speech and Hearing Disorders, 34(2) 146-151. MOSCOWITZ, B 2002: Bridging to family and community support for older adults and the domain management model. Topics in Stroke Rehabilitation, 9(3):75-86.

O' CONNELL, B; BAKER, L \& PROSSER, A 2003: The educational needs of caregivers of stroke survivors in acute and community settings. Journal of Neuroscience, 35(1):21-28.

PENN, C 1999: Pragmatic assessment and therapy for person's with brain damage: What have clinicians gleaned in two decades? Brain and Language, 68(3):535-552.

PENN, C 2002: Paying attention to conversation. Brain and Language, 71(1):185-189.

PENN, C; VNTER, A \& OGILVY, D 2001: Aphasia in Afrikaans: A preliminary analysis. Journal of Neurolinguistics, 14(2-4):111- 
132.

ROSENTHAL, R \& ROSNOW, RL 1991: Essentials of behavioral research: Methods and data analysis; $2^{\text {nd }}$ edition. New York: McGraw-Hill.

SASPI PROJECT TEAM. PREVALENCE OF STROKE IN RURAL SOUTH AFRICA 2004: Results from the Southern Africa Stroke Prevention Initiative (SASPI) Agincourt Field Site. Stroke, 35:627632.

SKILBECK, C 1992: Neuropsychological assessment in stroke, (In: CRAWFORD,JR; PARKER, DM \& McKINLAY, WW eds, A handbook of neuropsychological assessment. Hove: Psychology Press, pp. 339-359).

STARKSTEIN, SE \& ROBINSON, RG 1992: Neuropsychiatric aspects of cerebral vascular disorders. In Textbook of neuropsychiatry; $2^{\text {nd }}$ edition. Washington: American Psychiatric Press.

VAN VEENENDAAL, H; GRINSPUN, DR \& ADRIAANNSE, HP 1996: Educational needs of stroke survivors and their family members, as perceived by themselves and by health professionals. Patient Education and Counselling, 28(3):265-276.

WHYTE, EM \& MULSANT, BH 2002: Post stroke depression: Epidemiology, pathophysiology, and biological treatment. Biological Psychiatry, 52(3):253-264.

ZILLMER, EA \& SPIERS, MV 2001: Principles of neuropsychology. 